\title{
Personal Income Inequality and Aggregate Demand
}

\section{LAURA CARVALHO ARMON REZAI}

WORKING PAPER SERIES № 2014-23 
DEPARTMENT OF ECONOMICS, FEA-USP

WORKING PAPER № 2014-23

\title{
Personal Income Inequality and Aggregate Demand
}

Laura Carvalho (decarvalho.laura@gmail.com)

Armon Rezai (armon.rezai@wu.ac.at)

\begin{abstract}
:
This paper presents a theoretical and empirical investigation of how changes in the size distribution of income can affect aggregate demand and the demand regime of an economy. After presenting empirical evidence for the US economy that the propensity to save increases significantly from the bottom to the top quintile of wage earners, we demonstrate that more equal distributions always lead to higher output in the traditional neo-Kaleckian macroeconomic model. We also present conditions under which a reduction of income inequality among workers turns demand more wage-led. This view is supported by the results of an econometric study for the United States (1967-2010) which show that the rise after 1980 in income inequality has made the US economy more profit-led.
\end{abstract}

Keywords: Income inequality; demand regimes; Neo-Kaleckian model; personal and functional income distribution.

JEL Codes: D31; D33; E25; C32 


\title{
Personal income inequality and aggregate demand*
}

\author{
Laura Carvalho ${ }^{\dagger} \quad$ Armon Rezai ${ }^{\ddagger}$
}

October 21, 2014

\begin{abstract}
This paper presents a theoretical and empirical investigation of how changes in the size distribution of income can affect aggregate demand and the demand regime of an economy. After presenting empirical evidence for the US economy that the propensity to save increases significantly from the bottom to the top quintile of wage earners, we demonstrate that more equal distributions always lead to higher output in the traditional neo-Kaleckian macroeconomic model. We also present conditions under which a reduction of income inequality among workers turns demand more wage-led. This view is supported by the results of an econometric study for the United States (1967-2010) which show that the rise after 1980 in income inequality has made the US economy more profit-led.

Keywords: Income inequality, demand regimes, Neo-Kaleckian model, personal and functional income distribution.

JEL classification numbers: D31, D33, E25, C32
\end{abstract}

\footnotetext{
*We benefited from comments by Lance Taylor, Luca Zamparelli, Lucas Teixeira and two anonymous referees, as well as participants at the Eastern Economic Association Conference, the World Keynes Association Conference, the Brazilian Keynesian Association Conference and the Research Network Macroeconomics and Macroeconomic Policies Conference. The usual disclaimer applies.

$\dagger$ University of Sao Paulo, Department of Economics. Corresponding author: decarvalho.laura@gmail.com.

${ }^{\ddagger}$ Vienna University of Economics and Business, Department of Socio-Economics. Also affiliated with IIASA.
} 


\section{Introduction}

As the unprecedentedly large share of income appropriated by the top $1 \%$ was incorporated into the slogan of the Occupy Wall Street movement, the substantial rise in income inequality in the United States since the 1970s has become acknowledged by a wider public. In the economic literature, the main reference for this topic has recently become the book by Piketty (2014), even if in the particular case of the US, the main findings had been presented in Piketty and Saez (2003), who compiled a series for the top shares of income and wages between to conclude that income inequality has not only been increasing as a whole in the recent decades, but also that the working rich have replaced the rentiers at the top of the US income distribution. ${ }^{1}$ The role of managerial workers and their hybrid nature has been discussed seminally by Kalecki (1971) and Gordon (1996). Mohun (2012) presents recent evidence of the increase in the share of supervisory workers in total wages. This phenomenon serves as main motivation for this paper which aims at studying the implications of a rising inequality among wage earners for aggregate demand and its relationship to functional income distribution. The proponents of the Occupy Wall Street movement have, among other things, called for reform of the tax system to reduce income inequality. Our theoretical and empirical work traces through the generally positive macroeconomic implications of such policy proposals.

The macroeconomic effects of changing the functional distribution of income has been investigated extensively in both the theoretical and empirical economic literature. Already Keynes (1936) recognized the distributive effects on demand, e.g. in his condemnation of high-saving rentiers and bear speculators. Kalecki (1942) formalized the idea that savings propensities are different between profit earners and wage earners by assuming that saving is done exclusively by capitalists. Kaldor (1955-56) discusses the effects of differential saving rates on the distribution of income. This assumption has then been combined with Kaleckian mark-up pricing and an independent investment function in the so-called Neo-Kaleckian (or Kalecki-Steindl) models developed seminally by Rowthorn (1982), Dutt (1984), Taylor (1985) and Bhaduri and Marglin (1990). The crucial role played by the functional distribution of income in the determination of both consumption and investment in these models has given rise to the concepts of wage- and profit-led demand regimes, depending on which effect dominates.

Based on these ideas, empirical investigations of the overall effect of redistributing toward wages for different countries, time periods or specifications of demand and distributive variables have yielded contradicting results. Estimations of full macro models tend to show profit-led demand regimes (Franke, Flaschel, and Proaño, 2006; Chiarella, Franke, Flaschel, and Semmler, 2004; Barbosa-Filho and Taylor, 2006). Studies accommodating open economy effects (Bowles and Boyer, 1995; Naastepad and Storm, 2007; Ederer and Stockhammer, 2007; Hein and Vogel, 2008) find that small open economies (like the

\footnotetext{
${ }^{1}$ Palma (2011) extends the empirical analysis to a large number of countries and shows that inequality within countries rather than across country has been the major cause of the global trend in income inequality in the past decades.
} 
Netherlands or Austria) are more likely to be profit-led than large, relatively closed ones (like the US or the Euro area as a whole), even if domestic demandconsumption vs. investment - happens to be wage-led. As Gordon (1995) put it early on: "[...] the estimated coefficients from the net-export equation are instrumental in determining the final sign of the utilization function" (p. 361). ${ }^{2}$ In addition to the consideration of open economy effects, the original concepts of wage- and profit-led demand regimes have been further extended to include possible non-linearities in the relationship between the wage share and the degree of capacity utilization, as studied in Nikiforos and Foley (2012). These extensions are challenging previous empirical results and the very existence of stable demand regimes in particular countries over time. ${ }^{3}$

This paper extends the short-run Neo-Kaleckian framework to address a different kind of bias in such empirical and theoretical arguments: the size distribution of income. As the evidence presented in Piketty and Saez (2003) and Piketty (2014) highlights, rising inequality in the United States in the recent decades has been characterized by an increase in the share of income held by the top wage earners in addition to a falling wage share. One possible approach to this problem, taken by Dutt (1992) and Lavoie (1996), is to add an unproductive managerial class to the basic Kaleckian framework and examine the effects of wage inequality between managers and workers. Indeed, by also endogenizing the functional distribution of income and wage inequality itself, Tavani and Vasudevan (2014) find that wage-led regimes in terms of the distribution within the wage bill workers and co-exist with profit-led regimes in the functional income distribution. Palley (2013) proposes a model with three classes (workers, middle-class managers, and capitalist top managers) and studies the potential macroeconomic outcomes in terms of growth and distribution resulting from labor market conflict among these classes.

This paper has a similar motivation, but follows a different strategy. Instead of adding a third class to the Kaleckian framework, we provide both an empirical and a theoretical explanation for the savings rate to be an increasing function of wage inequality. Based on this extension, we ask two main questions: (i) how has this increase in the top share of income affected aggregate demand for a given level of the wage share? and (ii) did this increase contribute to the weak response of consumption to the wage share, thus turning the demand-regime more profit-led?

In an attempt to answer these questions, the paper is organized as follows. First, based on stylized facts regarding the relationship between savings rates and income inequality in the United States, Section 2 extends the standard

\footnotetext{
${ }^{2}$ Recent empirical work by Storm and Naastepad (2012), however, shows wage-led results for a large number of OECD countries, and attributes a more important role to investment than to net exports in the explanation of profit-led cases.

${ }^{3}$ An additional source of contention is the relationship between the demand regime and the business cycle. Barbosa-Filho and Taylor (2006) find Goodwin cycles in the US economy. The only dynamically stable combination rationalizing this pattern is a profit-led demand regime with a profit-squeeze distribution regime (see Taylor (2004) for details). Proao, Flaschel, Krolzig, and Diallo (2011) argue that this argument ignores the stabilizing role of monetary policy. Empirical findings in Rezai (2014a), however, reject their theoretical objection.
} 
Neo-Kaleckian model to account for different size distributions of wage income. While greater inequality necessarily reduces aggregate demand, we show that the effect of inequality on the demand regime of the economy depends on various parameters due to multiplier effects. Second, in Section 3, we present an econometric study examining the role of income inequality in determining the demand regime for the United States from 1967 to 2010. We find that the increase in inequality after 1980 has made the economy more profit-led.

\section{Macroeconomic effects of the size distribution of income}

\subsection{Empirical Motivation}

Most Neo-Kaleckian models assume that savings rates are different for different income classes. While this assumption is plausible, it is usually taken at face value without presenting empirical evidence. In this section we present such evidence for the US economy. In doing so, we use data for the quintiles of income before taxes from the Consumer Expenditure Survey as provided by the Bureau of Labor Statistics. ${ }^{4}$

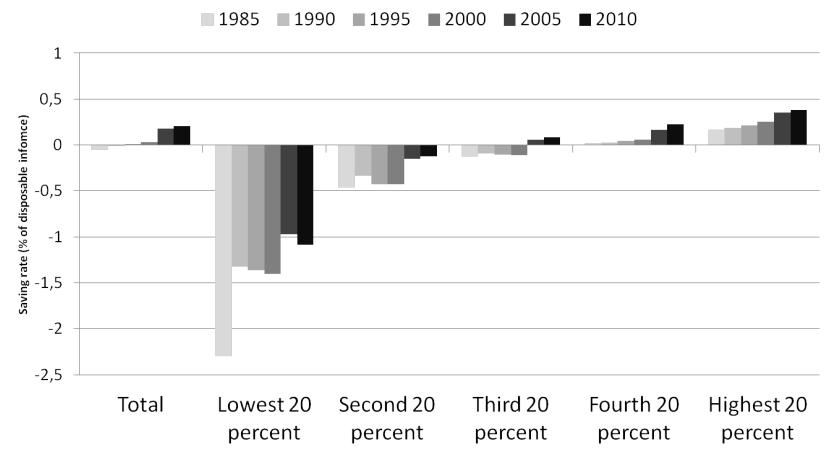

Figure 1: Savings rate per income quintile in the United States (1985-2010)

In Figure 1 we report the savings rates for each quintile of income after taxes. We computed these by calculating $(1-C / Y)$, where $C$ is the average annual expenditure and $Y$ is the average annual income of each quintile. Savings rates increase strongly with income. ${ }^{5}$ Whereas the top $20 \%$ saved about $40 \%$ of

\footnotetext{
${ }^{4}$ Tables from 1984 to 2010 are available at http://www.bls.gov/cex/. Data on the aggregate saving rate is conventionally taken from the NIPA. Taylor, Rezai, Kumar, Carvalho, and Barbosa-Filho (2014) discuss comparability of the two data sources.

${ }^{5}$ Not all income depicted in figure 1 is wage income but data limitations do not permit a separation of wage and profit income. Taylor, Rezai, Kumar, Carvalho, and BarbosaFilho (2014) disaggregate sources of household income showing that the ratio of income from finance to wage income rises dramatically from 1:0.002 for the bottom quintile over 1:0.06 for the middle $20 \%$ to 1:0.15 for the top quintile (and 1:0.25 for the top 1\%). The dispersion of
} 
their income in 2005, the middle $20 \%$ saved less than $10 \%$ and the bottom $20 \%$ borrowed to finance a substantial part of their expenditure. Personal income clearly matters for individual saving behavior and the distribution of income, therefore, clearly matters for aggregate saving.

The negative values observed for the lower quintiles show the importance of private debt accumulation in financing household expenditures in the US economy over the reported period. It is interesting to note that as the top $20 \%$ started to concentrate more of the total income after taxes (as shown in Figure 2 and discussed in Palma (2011)), their average savings rate has also increased.

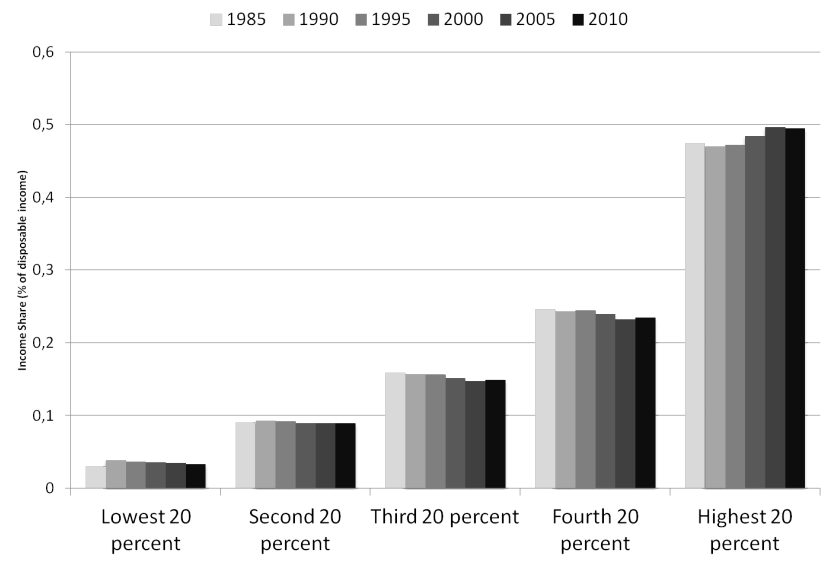

Figure 2: Income share per income quintile in the United States (1985-2010)

The distribution of income in the US economy has become more unequal over the past 30 years. Figure 2 presents the share of income after taxes held by each quintile for selected years. The figure shows how unequally income is distributed and how this inequality has been rising in the United States. Almost half of total income is held by the richest $20 \%$ in 2010 . These two observations serve as the main motivations for the theoretical and empirical analysis that follows.

The stylized facts have two main implications. First, as long as the paradox of thrift holds, an increase in the average savings rate as caused by a rise in income inequality between different categories of workers necessarily leads to lower aggregate demand. ${ }^{6}$ Second, the assumption of differential savings within the category of wage earners is clearly justified and needs to be accounted for in the conventional analysis of the relationship between changes in functional distribution of income and aggregate demand.

\footnotetext{
wage income is much greater than that of capital income.

${ }^{6}$ Palley (2010) discusses the theoretical possibility of higher inequality leading to higher aggregate demand if the saving function is convex. Our empirical data show that the saving function is generally concave and reject such "Veblen" dynamics.
} 


\subsection{Theoretical argument}

Most neo-Kaleckian models restrict themselves to differences in the saving behavior out of different sources of income. Their focus lies on the distribution between wages and profits, the functional income distribution. ${ }^{7}$ We find this surprising as these models can easily incorporate personal income inequality. We proceed by presenting an intuitive explanation of how income inequality affects the macroeconomy; a detailed application using a specific functional form for the saving function and a Pareto distribution of income is relegated to Appendix A.

Aggregate income is determined by independent investment and consumption/saving decisions. We retain the Steindlian-Kaldorian formulation for the investment function, in which investment $I$ depends positively on the rate of capacity utilization $u$ and on the rate of profit $r$, as well as on the autonomous component $\gamma_{0}$ representing so-called "animal spirits". We modify the saving function $S_{w}$ such that the propensity to save out of wages $s_{w}$ now depends on the size distribution of income among workers, captured in the inequality measure $\sigma$. The more unequal the distribution, the higher $\sigma$ and the higher the overall saving propensity: $s_{w}^{\prime}>0$. With this small, but important modification we can state the model equations. We use the model presented in chapter 5 of Taylor (2004). ${ }^{8}$

$$
\begin{aligned}
g^{i} & =\frac{I}{K}=\gamma_{0}+\gamma_{u} u+\gamma_{\pi} r=\gamma_{0}+\left(\gamma_{u}+\gamma_{\pi}(1-\psi)\right) u \\
g_{w}^{s} & =\frac{S_{w}}{K}=s_{w}[\sigma] \psi u \\
g_{\pi}^{s} & =\frac{S_{\pi}}{K}=s_{\pi} \pi u=s_{\pi}(1-\psi) u
\end{aligned}
$$

With $\lambda>0$, macroeconomic balance between savings and investment requires that in equilibrium

$$
\dot{u}=\lambda\left(g^{i}-\left(g_{w}^{s}+g_{\pi}^{s}\right)\right)=0 .
$$

Substituting equations (1) into (2), we obtain the standard expression for short-run equilibrium output

$$
u^{*}=\left.u\right|_{\dot{u}=0}=\frac{\gamma_{0}}{-\left(\gamma_{u}+\gamma_{\pi}(1-\psi)-s_{w}[\sigma] \psi-s_{\pi}(1-\psi)\right)}=\frac{\gamma_{0}}{\Delta}>0 .
$$

Output is determined by autonomous investment, $\gamma_{0}$, times the multiplier, $\Delta$. We assume that the Keynesian stability condition holds, i.e. $\frac{d \dot{u}}{d u}=-\Delta<0$.

\footnotetext{
${ }^{7}$ As mentioned in the introduction, one exception are models which incorporate a third class to the model to represent managers in the form of unproductive labor.

${ }^{8} \mathrm{As}$ in Taylor (2004), all variables will be given as ratios of the capital stock $K$. The rate of capacity utilization $u$ will be approximated by the output-capital ratio by assuming that capital productivity, namely the ratio of potential output to capital, is constant.
} 
Inequality affects the economy's overall saving decisions. As wage income is redistributed from low- to high-saving classes, leakage increases and aggregate demand falls as one would predict under the Paradox of Thrift. Put formally, this implies

$$
\frac{d u^{*}}{d \sigma}=\frac{\gamma_{0}}{\Delta^{2}} \frac{\partial \Delta}{\partial \sigma}=-u^{*} \frac{\psi}{\Delta} \frac{d s_{w}[\sigma]}{d \sigma}<0 .
$$

It is clear that redistribution among wage earners always stimulates demand and increases output. This effect is represented by a shift from point A to B in Figures 3 and 4 .

The usual debate on redistribution focuses on functional income redistribution, assuming equal distribution within factors. While this assumption might be innocuous for profit earners, the empirical evidence presented in section 2 demonstrates clearly that this does not hold for wage earners. Moreover, the assumption of unequal distribution of wages affects the response of output to the functional income redistribution, i.e. the demand regime. The demand regime of an economy is defined as

$$
\frac{d u^{*}}{d \psi}=\frac{u^{*}}{\Delta}\left[\left(s_{\pi}-s_{w}[\sigma]\right)-\gamma_{\pi}\right] \lessgtr 0 .
$$

If an increase in the wage share increases capacity utilization, the economy is said to be 'wage-led', if the opposite holds the economy is considered 'profit-led'. In this model, it is clear from expression (4), that the economy is wage-led if the saving differential between capitalists and workers $\left(s_{\pi}-s_{w}\right)$ is large and investment responds weakly to lower profitability as represented by a low $\gamma_{\pi}$. The first effect of functional income distribution decreases overall leakage in the economy, the second effect prevents injections to fall as $\psi$ increases.

Personal income distribution influences saving out of wages, it thereby also affects the demand regime of the economy, a feature that has received much attention over the past 20 years (Bowles and Boyer, 1995; Taylor, 2004; BarbosaFilho and Taylor, 2006; Chiarella, Franke, Flaschel, and Semmler, 2004; Franke, Flaschel, and Proaño, 2006; Ederer and Stockhammer, 2007; Hein and Vogel, 2008). Basic intuition tells us that an increase in inequality, caused by a rising share of income held by the top wage earners, increases the average saving out of wage income. This weakens the positive demand effects of a functional income redistribution, namely the fall in leakages. However, the changes in the savings rate also reduces the multiplier and capacity utilization with more subtle effects on investment and saving and, overall, ambiguous effects on the demand regime. To see this more clearly, we differentiate the expression (4) with respect to $\sigma$

$$
\frac{d \frac{d u^{*}}{d \psi}}{d \sigma}=-\frac{u^{*}}{\Delta} \frac{d s_{w}}{d \sigma}-\frac{d u^{*}}{d \psi} \frac{1}{\Delta} \frac{d s_{w}}{d \sigma}=-\frac{1}{\Delta}\left(u^{*}+2 \psi \frac{d u^{*}}{d \psi}\right) \frac{d s_{w}}{d \sigma} \lessgtr 0 .
$$

The first term in the inequality captures the immediate effect of saving out of wages on the demand regime: higher personal income inequality increases saving out of wages, which lowers the differential between saving out of profits and out 
of wages. Higher inequality pushes the demand regime toward more 'profitledness'. However, there are repercussions through the effect of inequality on the multiplier (saving and investment behavior). This mechanism is captured in the second term of the inequality in (5). This term depends on (and takes the sign of) the demand regime itself and is positive when the economy is wage-led and negative otherwise.

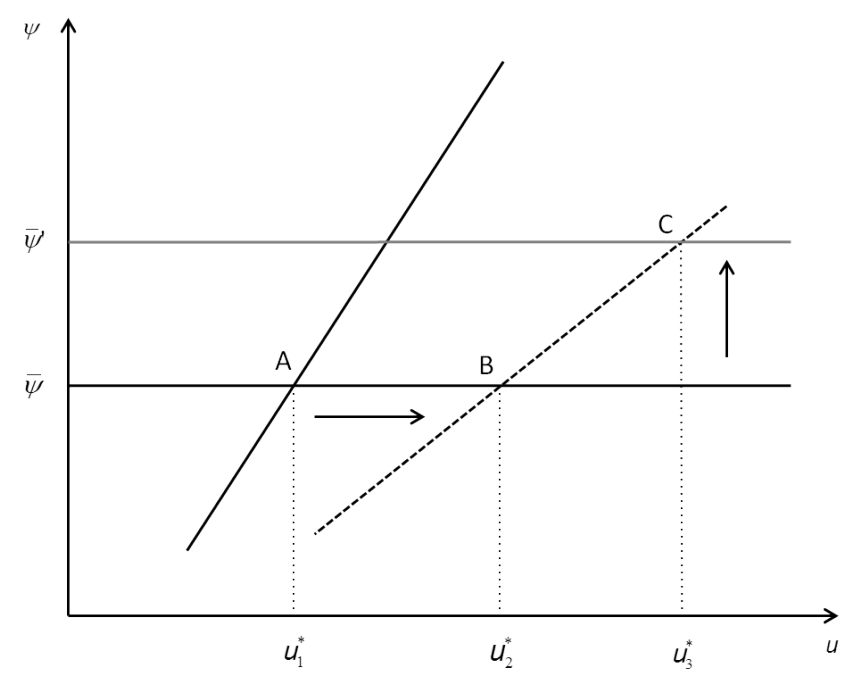

Figure 3: Response of aggregate demand to a reduction in wage inequality in the wage-led case

Hence, while egalitarian policies of income redistribution always increase capacity utilization in this model, their effect on the demand regime of the economy is ambiguous. If the economy is wage-led, redistribution always pushes the economy toward wage-ledness, as represented in Figure 3. This holds also true if the economy is "weakly profit-led". Only if the economy is "strongly profit-led" (strong investment responds to profitability and low functional saving differentials), personal income equality leads to more profit-ledness. The ambiguous change in the slope of the demand curve following a reduction in inequality in the profit-led scenario is represented in Figure 4, giving rise to different responses to an exogenous increase in the wage share (points $\mathrm{C}$ and D).

Barbosa-Filho and Taylor (2006) found that the US economy is profit-led. In this case, sole theoretical considerations cannot identify the effect of personal wage income inequality on the US economy's demand regime. In the next section we reestimate their model accounting for personal income inequality to inform this question empirically. ${ }^{9}$

\footnotetext{
${ }^{9}$ Others studies found that the US are wage-led (see literature review at the end of section 1). In this case, a reduction in wage inequality necessarily makes the economy more wage-led.
} 


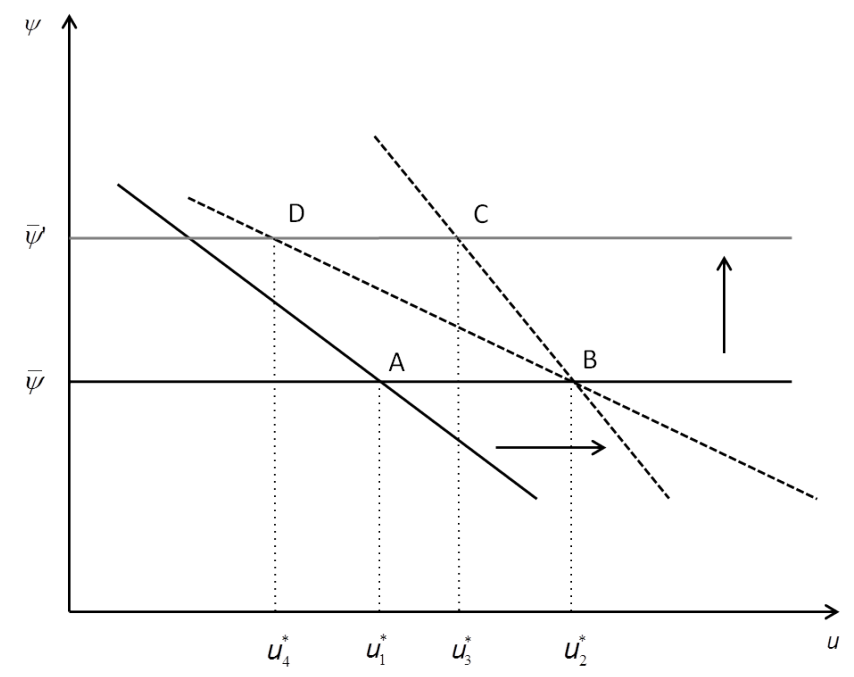

Figure 4: Response of aggregate demand to a reduction in wage inequality in the profit-led case

\section{Empirical analysis}

\subsection{Methodology and Data}

One of the main difficulties in estimating demand regimes lies in a potential endogeneity problem between measures of aggregate demand and income distribution. Indeed, as addressed by the literature focused on Goodwin cycles (Goodwin, 1967), income distribution not only affects, but may also be affected by aggregate demand if lower unemployment leads to an increase in the power of bargaining of workers. Two main approaches to address this problem can be found in the empirical literature. The first has involved the use of instrumental variables to control for each of the two directions of causality (see for instance Nikiforos and Foley (2012)). The second has been to estimate a system of dynamic equations simultaneously in a Vector Autoregression (VAR) or a Vector Error Correction (VEC) model, thus taking both directions of causality into account. The latter approach was the one used in Barbosa-Filho and Taylor (2006), who by means of a two-dimensional VAR model for capacity utilization and the wage share have found demand in the United States to be profit-led. Based on these results, the empirical study done in this section will investigate the role of income inequality in determining such demand regime by making use of a similar method: a two-dimensional Threshold Vector Autoregression (TVAR).

The idea of the threshold autoregressive model first developed by Tong

By using a model in our empirical study which finds a profit-led demand regime, we load the dice against this outcome. 
(1990) is to allow for a non-linearity in the dynamic relationship that is estimated. In other words, a threshold defined by the level of a certain variable is searched so as to minimize the sum of squared residuals and the estimated coefficients are different in the so-called low and high regimes. The regimeswitching (threshold) autoregressive model was extended to the multivariate context by Tsay (1998), giving rise to the Threshold Vector Autoregressive model (TVAR). ${ }^{10} \mathrm{~A}$ two-dimensional TVAR will be estimated for the degree of capacity utilization and the labor share, using a measure of the size distribution of income as the threshold variable. In other words, the model allows us to investigate whether the level of income inequality affects the response of aggregate demand to the functional distribution of income.

The quarterly series for the degree of capacity utilization was calculated as the ratio between actual output (obtained from the Bureau of Labor Statistics) and potential output. ${ }^{11}$ The series for the labor share is also provided from the Bureau of Labor Statistics at quarterly frequency. Both series will be used in logarithmic form in the estimations. Finally, income inequality will be measured by the Gini Coefficient provided by the U.S. Census Bureau (2010) ${ }^{12}$ from 1967 to 2010 annually. The conversion from annual to quarterly data was made by cubic interpolation.

A two-dimensional TVAR for the labor share and capacity utilization (in logarithmic form) was then estimated using two lags and the Gini coefficient as a threshold variable (lagged by one period), for the period 1967-2010. The threshold value was selected automatically based on a grid search which minimized the sum of squared residuals of the corresponding estimation. ${ }^{13}$

Linear accumulated impulse response functions to Cholesky standard deviation innovations were computed for the two regimes separately using the corresponding coefficients and the residuals of each TVAR ${ }^{14}$.

\section{$3.2 \quad$ Results}

The results of the TVAR estimation for the period 1967-2010 are presented in Table 1 in the Appendix. The selected threshold for the Gini coefficient determining the low and high inequality regimes was 0.406 , which corresponds to the value attained in 1981 . The low (high) inequality regime, which comprises $32.9 \%(67.1 \%)$ of the total of observations, thus corresponds to the years before (after) 1981. Both regimes are shown to be characterized by profit-led demand,

\footnotetext{
${ }^{10}$ Different types of models have been developed to address non-linearities in time series since Tong's original threshold autoregressive model. See Hansen (2011) for a survey of such developments applied to economics.

${ }^{11}$ As in Barbosa-Filho and Taylor (2006), the series for potential output was derived from the output series using a Hodrick-Prescott filter.

${ }^{12}$ Current Population Survey, Annual Social and Economic Supplements, available at http://www.census.gov/hhes/www/income/data/historical/household/h04.html

${ }^{13}$ The $\mathrm{R}$ program is available from authors upon request.

${ }^{14}$ Since exogenous shocks may generate a switch from one regime to the other, generalized non-linear impulse response functions based on initial conditions are developed in Koop, Pesaran, and Potter (1996), but will not be estimated here.
} 
with the total effect of the labor share $\Psi$ in the equation for capacity utilization $u$ being negative even if it is positive for the first lag (due to higher consumption).

Figure 5 presents the accumulated response of the degree of capacity utilization to a standard deviation shock in the labor share for the low and high inequality regimes ${ }^{15}$. The figure shows that in the high inequality regime the impact of an increase in the wage share in capacity utilization is more negative. In other words, results of the TVAR suggest that the increase in income inequality has turned demand more profit-led in the United States over this period. Hence, these results seem to confirm the theoretical argument presented in the previous section which corresponds to the weakly profit-led case.

Our results do not capture the full picture, namely the joint roles of personal income inequality, open economy effects and consumer debt in the determination of the (possibly non-linear) relationship between functional income distribution and the level of economic activity. Yet, if we consider that a rise in inequality may also increase the level of consumer debt, high inequality periods would tend to be more wage-led, as the rise in debt would reduce the fall in consumption following a redistribution toward profits. Hence, controlling for this channel could have the potential effect of strengthening our main result, thus stressing the importance of savings differentials withing wage earners as a transmission mechanism.

\section{Discussion}

Income distribution has become more unequal in the past decades, reversing much of the gains from post-WWII. This holds true for shifts toward profits in the functional income distribution and shifts toward high-income earners within wage income. While these shifts have gained the attention of the wider public through the 'Occupy Wall Street' movement, the academic debate has focused almost exclusively on the impact of changes in the functional income distribution.

Empirical evidence clearly shows that wage earners have different saving rates depending on the disposable income. Saving rates rise from negative for the bottom $20 \%$ to as high as $40 \%$ for the top $20 \%$ in the year 2010. Given these differences in saving behavior, we analyze the effects of recent increases in wage income inequality on aggregate demand and the economy's demand regime.

While the Paradox of Thrift predicts that output falls as inequality rises, the effects of changes in the functional income distribution on output under different wage income distributions is ambiguous. Higher wage equality makes the economy more wage-led. If the economy is profit-led, the sign of this effect is ambiguous and depends on the level of demand regime itself. These nonlinear effects in the IS curve complements recent work on non-linearities by Nikiforos and Foley (2012) who present empirical evidence for a non-linear distribution schedule.

\footnotetext{
${ }^{15}$ The impulse response functions for the other direction of causality - the effect of aggregate demand on distribution - are presented in the appendix but will not be analyzed here.
} 


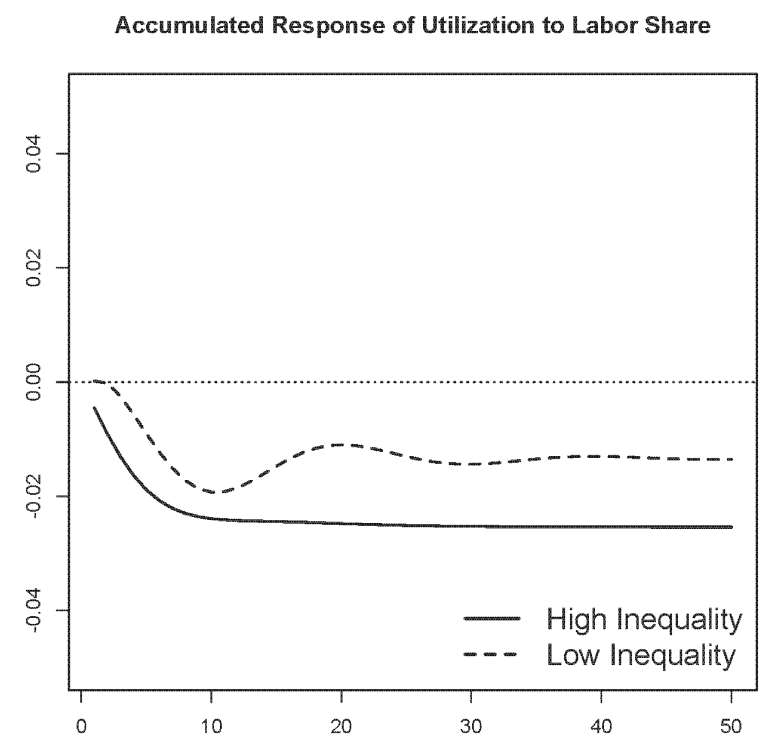

Figure 5: Accumulated impulse response function of the degree of capacity utilization to a standard deviation shock in the labor share in the low and high inequality regimes for the United States (1967-2010) 
Since our theoretical model cannot clearly identify the effects of wage income inequality on the demand regime, we proceed empirically by estimating a nonlinear version of the model by Barbosa-Filho and Taylor (2006) in order to determine the effect of income inequality on the demand regime for the postWWII US economy. The linear estimation by the authors had suggested that the US economy is profit-led. Our estimations show that a large part of this result is due to the high inequality level after 1981.

These findings add to recent evidence that the standard Kaleckian model incompletely captures interactions between demand and distribution when applied to today's advanced economies: Dutt (2006) extends the model to account for consumer debt, illustrating the positive short run of consumer borrowing on demand and the potentially negative implications for future growth and financial stability. Rezai (2014b) and von Arnim, Tavani, and de Carvalho (2012) highlight the importance of open-economy issues. We introduce personal income distribution as a third omitted and potentially important bias.

Our results have clear and important implications for economic policy. As the Great Recession keeps unfolding and the political climate shifts increasingly against traditional economic stimuli to prop up demand, taxes-and-transfer schemes can prove effective. While the demand effects of increases in money wages might be repressed by concurrent increases in inflation under mark-up pricing rules, the demand effect of redistribution from profits toward wages depends on the economy's demand regime. Our findings suggest that egalitarian policies within wage earners increase demand irrespective of such considerations. Lowering wage income inequality always increases aggregate demand due to the Paradox of Thrift. Moreover, lowering inequality among wage earners can, and in fact in the US economy does, tilt the economy in a wage-led direction, providing arguments for progressive and expansionary policy in the form of redistribution in functional income on economic - rather than mere social grounds in the future. 


\section{References}

Barbosa-Filho, N., and L. Taylor (2006): "Distributive And Demand Cycles In The Us Economy-A Structuralist Goodwin Model," Metroeconomica, 57(3), 389-411.

Bhaduri, A., And S. Marglin (1990): "Unemployment and the Real Wage: The Economic Basis for Contesting Political Ideologies," Cambridge Journal of Economics, 14(4), 375-393.

Bowles, S., ANd R. Boyer (1995): "Wages, aggregate demand, and employment in an open economy," in Macroeconomic Policy After the Conservative Era, ed. by G. Epstein, and H. Gintis. Cambridge University Press, Cambridge, UK.

Chiarella, C., R. Franke, P. Flaschel, and W. Semmler (2004): Quantitative and Empirical Analysis of Nonlinear Dynamic Macromodels, Volume 277. Harvard University Press, Amsterdam.

DutT, A. K. (1984): "Stagnation, Income Distribution and Monopoly Power," Cambridge Journal of Economics, 8(1), 25-40.

(1992): "Stagnation, Growth, and Unproductive Activity," in The Economic Surplus in Advanced Economies, ed. by J. Davies. Edward Elgar, Aldershot.

(2006): "Maturity, Stagnation And Consumer Debt: A Steindlian Approach," Metroeconomica, 57(3), 339-364.

Ederer, S., and E. Stockhammer (2007): "Wages and aggregate demand in France: an empirical investigation," in Money, Distribution and Economic Policy: Alternatives to Orthodox Macroeconomics, ed. by E. Elgar. Cambridge University Press, Cheltenham.

Franke, R., P. Flaschel, and C. R. Proaño (2006): "Wage-price dynamics and income distribution in a semi-structural Keynes-Goodwin model," Structural Change and Economic Dynamics, 17(4), 452-465.

Goodwin, R. (1967): "A Growth Cycle," in Socialism, Capitalism, and Growth, ed. by C. Feinstein. Harvard University Press, Cambridge, Massachusetts.

Gordon, D. (1995): "Growth, distribution, and the rules of the game: social structuralist macro foundations for a democratic economic policy," in Macroeconomic Policy After the Conservative Era, ed. by G. Epstein, and H. Gintis, p. 335383. Cambridge University Press, Cambridge, UK.

Gordon, D. (1996): Fat and Mean: The Corporate Squeeze of Working Americans and the Myth of Managerial 'Downsizing'. The Free Press, New York, NY. 
Hansen, B. (2011): "Threshold autoregression in economics," Statistics and its interface, 17, 123-127.

Hein, E., ANd L. Vogel (2008): "Distribution and growth reconsidered: empirical results for six OECD countries," Cambridge Journal of Economics, $32(3), 479-511$.

KALDoR, N. (1955-56): "Alternative Theories of Distribution," The Review of Economic Studies, 23(2), 83-100.

Kalecki, M. (1942): "A Theory of Profits," The Economic Journal, 52(206207), 258-267.

(1971): "Class struggle and the distribution of national income," Kyklos, 24(1), 1-9.

Keynes, J. (1936): The General Theory of Employment, Interest and Money. Palgrave Macmillan, London.

Koop, G., M. H. Pesaran, and S. M. Potter (1996): "Impulse response analysis in nonlinear multivariate models," Journal of Econometrics, 74(1), $119-147$.

Lavoie, M. (1996): "Unproductive Outlays and Capital Accumulation with Target-return Pricing," Review of Social Economy, 54(3), 303-322.

Mohun, S. (2012): "Unproductive Labor in the US Economy," Discussion paper, mimeo.

NaAstepad, C. W., and S. Storm (2007): "OECD demand regimes (19602000)," Journal of Post Keynesian Economics, 29(2), 211-246.

Nikiforos, M., and D. K. Foley (2012): "Distribution And Capacity Utilization: Conceptual Issues And Empirical Evidence," Metroeconomica, 63(1), 200-229.

Palley, T. (2010): "The Relative Permanent Income Theory of Consumption: A Synthetic Keynes-Duesenberry-Friedman Model," Review of Political Economy, 22(1), 41-56.

(2013): "A neo-Kaleckian-Goodwin model of capitalist economic growth: monopoly power, managerial pay and labour market conflict," Cambridge Journal of Economics, p. forthcoming.

Palma, J. (2011): "Homogeneous Middles vs. Heterogeneous Tails, and the End of the Inverted-U: It's All About the Share of the Rich," Development and Change, 42(1), 97-153.

Piketty, T. (2014): Capital in the twenty-first century. Harvard University Press: Cambridge. 
Piketty, T., and E. Saez (2003): "Income Inequality In The United States, 1913-1998," The Quarterly Journal of Economics, 118(1), 1-39.

Proao, C., P. Flaschel, H. Krolzig, and M. Diallo (2011): "Monetary Policy and Macroeconomic Stability under Alternative Demand Regimes," Cambridge Journal of Economics, 35(3), 569-585.

Rezai, A. (2014a): "Cycles of Demand and Distribution and Monetary Policy in the US Economy," Journal of Post Keynesian Economics, 36, 231-250.

- (2014b): "Demand and distribution of integrated economies," Cambridge Journal of Economics, p. forthcoming.

Rowthorn, R. (1982): "Demand, real wages and economic growth," Studi Economici, 1(18), 3-54.

Storm, S., and C. W. M. NaAstepad (2012): Macroeconomics Beyond the NAIRU. Harvard University Press, Cambridge, Massachusetts.

Tavani, D., and R. VAsudevan (2014): "Capitalists, workers, and managers: Wage inequality and effective demand," Structural Change and Economic Dynamics, 30(0), 120 - 131.

TAYlor, L. (1985): "A Stagnationist Model of Economic Growth," Cambridge Journal of Economics, 9(4), 383-403.

(2004): Reconstructing Macroeconomics. Structuralist Proposals and Critiques of the Mainstream. Harvard University Press, Cambridge, Massachusetts.

Taylor, L., A. Rezai, R. Kumar, L. Carvalho, and N. Barbosa-Filho (2014): "US Size Distribution and the Macroeconomy, 1986-2009," in Macroeconomics and Development: Roberto Frenkel and the Economics of Latin America, ed. by M. Damill, M. Rapetti, and G. Rozenwurcel, p. ch. 15. Columbia University Press, New York, NY.

Tong, H. (1990): Non-linear time series: a dynamic system approach. Clarendon Press, Cambridge, Massachusetts.

Tsay, R. S. (1998): "Testing and Modeling Multivariate Threshold Models," Journal of the American Statistical Association, 93(443), 1188-1202.

von Arnim, R., D. Tavani, and L. de Carvalho (2012): "Globalization as coordination failure: A Keynesian perspective," Department of Economics Working Paper 02/2012, New School for Social Research.

YAKOVEnKo, V. (2012): "Applications of statistical mechanics to economics: Entropic origin of the probability distributions of money, income, and energy consumption," in Analytical Insights and Social Fairness: Economic Essays in the Spirit of Duncan K. Foley, ed. by L. Taylor, A. Rezai, and T. Michl. Routledge. 


\section{Appendix}

\section{A An application of the model}

In this section we present the derivation of the aggregate saving function for an economy in which wage income follows a Pareto (Type I) distribution. We pick the Pareto distribution for three reasons: first, since income cannot be negative, the probability density function needs a lower limit under which it has measure 0 . This limit is defined as parameter $k$ for the Pareto distribution. Second, Yakovenko (2012) demonstrates that the distribution of personal income in the US exhibits a 'fat' tail. The Pareto distribution has such a fat tail. Third, closed form solutions can be derived for the Lorenz curve and the GINI coefficient when income follows the Pareto distribution.

Let personal income equal $y>\kappa$, then the probability density function (pdf) of a Pareto distribution is

$$
f(y)=\frac{\frac{k \alpha}{y^{\alpha-1}} \text { if } \kappa \leq y}{0 \quad \text { if } \kappa>y}
$$

The median, $\mu$, and median, $\nu$, of a Pareto are defined as

$$
\mu=\frac{\kappa \alpha}{\alpha-1} \text { for } \alpha>1 \quad \text { and } \quad \nu=2^{1 / \alpha} \kappa
$$

We assume that personal saving decision of household $i$ depends the income of household $i, y_{i}$, and the income of the median household, $y_{\nu}$. Household $i$ 's saving is defined as

$$
S_{i}=a_{0} y_{i}+a_{1}\left(y_{i}-y_{\nu}\right)
$$

Aggregate saving is the sum of all saving:

$S_{w}=\int\left[a_{0} y_{i}+a_{1}\left(y_{i}-y_{\nu}\right)\right] f(y) d y=a_{0} \mu+a_{1}(\mu-\nu)=\left[a_{0}+a_{1}\left(1-\frac{\nu}{\mu}\right)\right] \mu$.

$\mu$ eqals average income, which has to be related to the macro variables of the Kaleckian model of section 2. Average income times population size has to equal aggregate wage income: $\mu L \equiv \psi X$ or $\mu \equiv \psi u k$. A Pareto distribution has 2 degrees of freedom, $\kappa$ and $\alpha$. We use $\kappa$ to ensure that changes in the distribution are mean-preserving (i.e. the identity is satisfied),

$$
\kappa \equiv \frac{\alpha-1}{\alpha} \psi u k
$$

Population size is normalized to $1, L \equiv 1$. Substituting this expression and the expression for the Gini coefficient, $\Gamma=\frac{1}{2 \alpha-1}$, into the saving function, we obtain a saving function of the form used in our empirical and theoretical model

$\frac{S_{w}}{K}=\left[a_{0}+a_{1}\left(1-\frac{2^{1 / \alpha} \alpha-1}{\alpha}\right)\right] \psi u=\left[a_{0}+a_{1}\left(1-4^{\frac{\Gamma}{1+\Gamma}} \frac{(1-\Gamma)}{1+\Gamma}\right)\right] \psi u=s_{w}[\Gamma] \psi u$. 
with $s_{w}[\Gamma]$ the average propensity to save (APS). The second parameter of the Pareto distribution, $\Gamma$, captures the degree of wage income inequality. As $\Gamma$ increases, more income is concentrated at the bottom and the more equal wage income distribution.

$s_{w}[\Gamma]$ has both properties used for the comparative statics used in section 2: first, average aggregate saving rises as the economy becomes more unequal and, second, under equally distributed income, the analysis conflates to the traditional assumption of a constant APS:

$$
\begin{aligned}
\frac{d s_{w}}{d \Gamma} & <0 \\
\lim _{\Gamma \rightarrow 0} s_{w} & \rightarrow a_{0} \\
\lim _{\Gamma \rightarrow 1} s_{w} & \rightarrow a_{0}+a_{1}
\end{aligned}
$$

Our results therefore hold for specific (and realistic) assumptions on the distribution of income across wage earners. The results also demonstrate how our model is a generalize variant of the standard Kalecki-Steindl growth model.

\section{B Econometric results}

\begin{tabular}{lllll}
\hline \multicolumn{2}{c}{ Equation for $u$} & \multicolumn{2}{c}{ Equation for $\Psi$} \\
\hline & Low Inequality & High Inequality & Low Inequality & High Inequality \\
\hline$u_{-1}$ & $1.3095^{* * *}$ & $1.4477^{* * *}$ & -0.0039 & 0.0732 \\
$u_{-2}$ & $-0.5941^{* * *}$ & $-0.6297^{* * *}$ & $0.2071^{*}$ & 0.0948 \\
$\Psi_{-1}$ & $0.8536^{* * *}$ & $0.2956^{* *}$ & $0.5271^{* * *}$ & $0.7473^{* * *}$ \\
$\Psi_{-2}$ & $-0.9124^{* * *}$ & $-0.3181^{* *}$ & 0.1603 & $0.2652^{* *}$ \\
Intercept & 0.2456 & 0.0932 & $1.3061^{* * *}$ & -0.053 \\
\hline Signif. Codes: ${ }^{* * *} 1 \% ; * * 5 \% ;{ }^{*} 10 \%$ & & \\
Threshold value: 0.406469 & \\
Percentage of Observations in each regime: $32.9 \% 67.1 \%$ & \\
\hline
\end{tabular}

Table 1: Results of the two-dimensional TVAR estimation for the United States (1967-2010) using the Gini Coefficient as a threshold. 


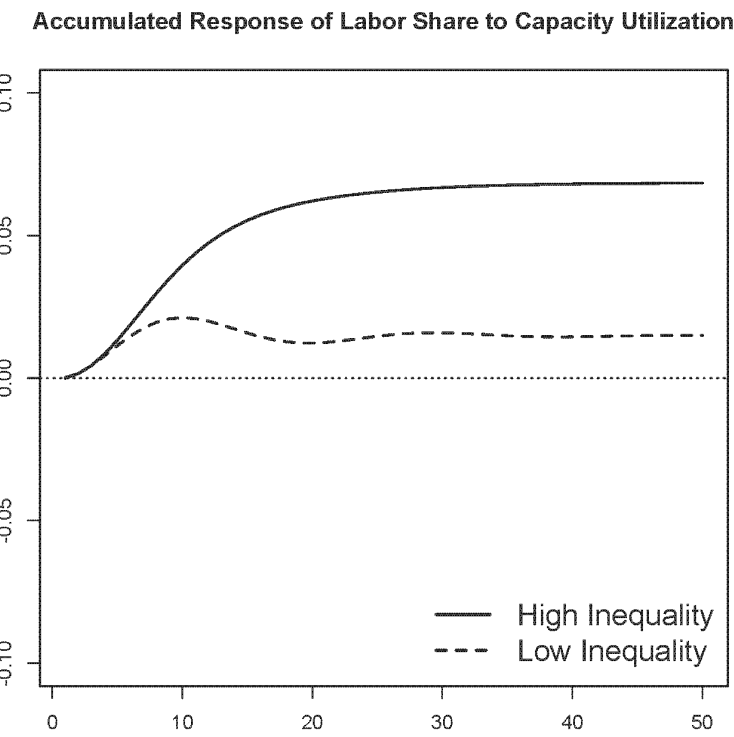

Figure 6: Accumulated impulse response function of the labor share to a standard deviation shock in the degree of capacity utilization in the low and high inequality regimes for the United States (1967-2010) 